\title{
Pathogenetic approach to the treatment of functional disorders of the gastrointestinal tract and their intersection: results of the Russian observation retrospective program COMFORT
}

\author{
Vladimir T. Ivashkin', Elena A. Poluektova', Alexey B. Glazunov², Mikhail A. Putilovskiy ${ }^{2}$ and Oleg I. Epstein ${ }^{3}$
}

\begin{abstract}
Background: The aim of this study was to investigate the efficacy and safety of the novel complex drug, consisting of released-active form of antibodies to S-100 protein, tumor necrosis factor-a and histamine, (Kolofort) under outpatient conditions in patients with functional dyspepsia (FD), irritable bowel syndrome (IBS), and FD-IBS overlap.

Methods: The subjects of the observational noninterventional retrospective program were the data of 14,362 outpatient records of patients with diagnosed FD, IBS, and/or overlap, who were observed by gastroenterologists from November 01, 2017, through March 30, 2018, who received the drug Kolofort in monotherapy for 12 weeks, 2 tablets twice a day. To assess the presence and severity of symptoms of functional gastrointestinal disorders (FGID), the " $7 * 7^{*}$ " questionnaire developed by a working group from the Russian Gastroenterological Association was used. The evaluated parameters included the proportion of patients: who had a 50\% or more reduction in the total score; who have switched to the less severe category of the condition; who have switched to the "healthy" or "borderline ill" severity categories; and the change in the score in domains 1-7.

Results: The final efficacy analysis included data from 9254 patients. A decrease in the total score by $50 \%$ or more was observed in $80.45 \%$ of patients with FD, $79.02 \%$ of patients with IBS, and in $83 \%$ of patients with both IBS and FD. Switch to a lower severity category of the condition at the end of therapy was noted in $93.35 \%$ of patients with FD, in $93.80 \%$ of cases in patients with IBS, and in $96.17 \%$ of cases in patients with a combination of IBS and FD. A total of 94 adverse events (AEs) were reported in 80 patients (0.65\%).
\end{abstract}

Conclusion: The COMFORT program has demonstrated the positive effect of treatment in the majority of patients with IBS and FD and their combination in real clinical practice.

Keywords: Irritable bowel syndrome, Functional dyspepsia, Overlap of irritable bowel syndrome and functional dyspepsia, "7*7" questionnaire

\footnotetext{
* Correspondence: makarovaea@materiamedica.ru

${ }^{2}$ Department of Medical Information, Research and Production Company

Materia Medica Holding LLC "NPF" MATERIA MEDICA HOLDING, 9, 3rd

Samotyochny Per, Moscow, Russian Federation 127473

Full list of author information is available at the end of the article
}

(c) The Author(s). 2019 Open Access This article is distributed under the terms of the Creative Commons Attribution 4.0 International License (http://creativecommons.org/licenses/by/4.0/), which permits unrestricted use, distribution, and

reproduction in any medium, provided you give appropriate credit to the original author(s) and the source, provide a link to the Creative Commons license, and indicate if changes were made. The Creative Commons Public Domain Dedication waiver (http://creativecommons.org/publicdomain/zero/1.0/) applies to the data made available in this article, unless otherwise stated. 


\section{Background}

A variety of clinical forms and the heterogeneity of the pathogenetic mechanisms of functional gastrointestinal disorders (FGID) complicate the diagnosis and choice of an effective treatment regimen [1]. Irrational pharmacotherapy, the prescription of symptomatic drugs that do not have indications for treatment of the FGID, leads to polypharmacy, low patient adherence to treatment, and an increased risk of developing adverse events (AE) [2-5].

Particular difficulties in the treatment of FGID arise from the combination of their various forms [3]. The association of IBS FD is most commonly observed [6]. Such patients have elevated visceral hypersensitivity, greater severity of gastrointestinal symptoms, and lower quality of life than patients with a single FGID [7, 8].

In the FD, dysfunction of the digestive tract organs is often combined with a mental illness $[9,10]$. According to the literature, up to $90 \%$ of patients with FGID have concomitant psychiatric disorders $[11,12]$. This neuropsychological component also serves as a key link in the pathogenesis of the combination of FD and IBS $[13,14]$.

Chronic inflammation in the gastrointestinal tract (GIT) caused by imbalances of pro-inflammatory and anti-inflammatory factors (tumor necrosis factor- $\alpha$ (TNF- $\alpha$ ); interleukins (IL) IL-2, IL-6, IL-10, and histamine) plays an important role in the development and progression of FGID $[15,16]$.

Due to the pathogenetic mechanisms associated with impaired motor function of the GIT and a reduced threshold for the perception of stimuli, abdominal pain appears to be the main symptom of most of FGID $[17,18]$.

Currently, various symptomatic and disease-modifying approaches are being used for the treatment of FGID: antispasmodics, proton pump inhibitors, drugs that relieve diarrhea/constipation, prokinetics, probiotics, antidepressants, antagonists of $5-\mathrm{HT}_{3}$ and $5-\mathrm{HT}_{4}$ receptors, opioid receptor agonists, and selective activators of C-2 chloride channels [19-21]. Most of these drugs, however, are not always able to effectively solve the problems of patients. In this regard, in the routine practice of gastroenterologists, therapists, and general practitioners, there is a need for a multi-targeted drug affecting the main pathogenesis of FGID.

For the treatment of FGID, the combination of releasedactive form of antibodies to S-100 protein, TNF- $\alpha$ and histamine (RAF of Abs to S 100, Abs to TNF- $\alpha$ and Abs to $\mathrm{H})$, a pathogenetically targeted drug Kolofort, was developed by the Research and Production Company Materia Medica Holding (LLC NPF" MATERIA MEDICA HOLDING") Moscow, Russia and introduced into practical medicine. The RAF of Abs in the drug provide an antiinflammatory, spasmolytic, and anxiolytic effect [22].

It was established experimentally that the antispasmodic effect of the combination of RAF of Abs to S 100, Abs to TNF- $\alpha$ and Abs to $H$ is due to the relaxation of smooth muscles and a decrease in the tone of the walls of the stomach and intestines. Anti-inflammatory properties are realized due to the effect of the drug on the production of TNF- $\alpha$ and it's associated cytokines. The positive effect of the drug components on the nervous and humoral regulation of functions of the gastrointestinal tract has been confirmed [22].

A randomized, placebo-controlled clinical study has demonstrated the efficacy and safety of combination of RAF of Abs to S 100, Abs to TNF- $\alpha$ and Abs to $H$ for the treatment of FGID [22, 23]. At the same time, there was no large-scale population-based research of the combination of RAF of Abs to S 100, Abs to TNF- $\alpha$ and $\mathrm{Abs}$ to $\mathrm{H}$ under outpatient conditions in patients with FD, IBS, and their combination.

\section{Methods \\ Study design}

This was an observational nonintervention retrospective program to study the efficacy and safety of the use of the combination of RAF of Abs to S 100, Abs to TNF- $\alpha$ and $\mathrm{Abs}$ to $\mathrm{H}$ in patients with FD, IBS, and their combination in outpatient settings. In order to obtain a representative sample, data of 14,362 patients from 67 cities of the Russian Federation were collected. Four hundred seventy-three gastroenterologists participated in the Russian Observational Program COMFORT.

The study included the analysis of medical records of outpatients 18 and older, of both genders, diagnosed with FD or IBS or with a combination of FD and IBS, as verified by their medical history. To be included in the study, patients had to be observed by a gastroenterologist from November 01, 2017, through March 30, 2018. Patients were examined in accordance with the recommendations of the Russian Gastroenterological Association for the treatment of FD and IBS.

FD is characterized by the presence of permanent or periodic symptoms of dyspepsia, such as upper abdominal pain, nausea, a feeling of burning in the stomach area, fullness in the stomach, early satiety, which appeared at least 6 months before diagnosis, lasting at least 3 months, in the absence of an organic disease that explains the appearance of these symptoms.

Based on the Rome IV Criteria IBS is manifested by a symptom-based scheme requiring that patient complains of abdominal pain on average at least once per week and that pain is associated with two or more of the following characteristics: it is related to defecation; to a change in the frequency of stool; or it is connected with a change in the form of the stool. These criteria should be fulfilled for the last 3 months, with symptom onset at least 6 months before diagnosis.

In addition, previous treatment with other drugs have to be continued and during the observation period patients to 
be treated with the combination of RAF of Abs to S 100, Abs to TNF- $\alpha$ and Abs to $H$ for 12 weeks, 2 tablets twice a day in accordance with instruction for medical use.

The COMFORT Observation Program has been approved by the Independent Interdisciplinary Committee for the Ethical Review of Clinical Studies of the Russian Federation. The observational type of the study did not imply additional methods of laboratory or instrumental examination for the inclusion of patient's data in the program. Patients with decompensated or unstable somatic disease, patients showing alarm symptoms, patients with significant accompanying gastrointestinal or other diseases, pregnant or nursing women were not admitted to the study.

To assess the presence and severity of symptoms characteristic of FGID, the "7*7" questionnaire was used. The "7"7" questionnaire was developed by the Russian Gastroenterological Association based on clinical symptoms described in the Rome III criteria and recommended for use by gastroenterologists in routine practice to assess the presence and severity of the seven main symptoms of FGID observed over the past 7 days [24]. The first four domains in the "7*7" questionnaire are considered as symptoms of FD; domains 5 through 7 characterize IBS symptoms.

Patients completed the questionnaire before and 3 months after the therapy with the combination of RAF of Abs to $S 100$, Abs to TNF- $\alpha$ and Abs to H. The severity of the condition was expressed by the total score and the patients were allocated into one of the six groups: $0-1-$ normal (healthy); 2-6 - borderline ill; 7-12 - mildly ill; 13-18 - moderately ill; 19-24 - markedly ill; > 25 - severely ill.

The total score of domains 1 and 2 allows to estimate the intensity of abdominal pain; the total score of domains 3 and 4 allows to estimate the severity of symptoms of early satiety. The dynamics of points of the 5 th domain allow us to estimate the intensity of pain, decreasing after bowel emptying, the 6th domain allows us to estimate the intensity of abdominal distention, and the 7th domain allows us to estimate the characteristics of the stool.

\section{Evaluated parameters}

1) The proportion of patients who had a decrease in the total score according to the "7"7" questionnaire by $50 \%$ or more after 12 weeks of therapy in the groups with FD, IBS, and FD-IBS overlap.

2) The proportion of patients who switched to a lower severity category of the condition according to the "7*7" questionnaire after 12 weeks of therapy in the groups with FD, IBS, and FD-IBS overlap.

3) The proportion of patients who switched to the "healthy" or "borderline ill" severity categories according to the "7*7" questionnaire after 12 weeks of therapy in the groups with FD, IBS, and FD-IBS overlap.
4) The change in the average score in domains 1-7 according to the "7"7" questionnaire after 12 weeks of therapy in the groups with FD, IBS, and FD-IBS overlap.

\section{Methods of statistical analysis}

No inferential and statistical analyses was used due to absence of groups of comparison to the treatment group. Continuous variables are presented as estimates of mean and categorical variables are presented as a number and percentage of patients in the respective categories. Data from patients with missing values were not included in the analysis.

\section{Results}

\section{Patient characteristics}

A total of 14,362 patients participated in the study. The final efficacy analysis included data from 9254 patients. The data of 5108 patients were not used to assess the effectiveness of the therapy, since 1645 patients had organic gastrointestinal diseases besides the presence of FGID, and 3463 patients had missing data that did not allow for evaluating the dynamics of symptoms. The safety analysis took into account the data of all 14,362 patients.

Among the patients included in the efficacy analysis, 2404 patients were diagnosed with FD, 5909 patients had IBS, and 941 patients had overlapping IBS and FD.

The average age of patients with FD was $33.5 \pm 11.2$ years, with IBS $-37.8 \pm 12.7$ years, and with overlapping IBS and FD - $36.3 \pm 11.3$ years.

Among the participants of the COMFORT program, women prevailed (5898 patients). In the group of patients with FD, there were 1437 (59.78\%) women and 967 (40.22\%) men, in the group of IBS - 3849 (65.14\%) women and $2060(34.86 \%)$ men, and in the group of patients with overlapping IBS and FD, there were 612 (65.04\%) women and 329 (34.96\%) men.

By severity levels, patients were distributed as follows: 383 patients (4.13\%) "borderline ill" (total score 2-6), 2822 patients (30.60\%) "mildly ill" (total score 7-12), 3236 patients $(34.96 \%)$ "moderately ill" (total score $13-$ 18), 1708 patients (18.45\%) "markedly ill" (total score 19-24), 1105 patients (11.94\%) "severely ill" (total score $>25)$ (Table 1).

The distribution of patients by categories of severity and by various types of diseases is presented in Table 2 .

\section{Efficacy evaluation}

According to the "7*7" questionnaire after 12 weeks of treatment with the combination of RAF of Abs to S 100, Abs to TNF- $\alpha$ and Abs to $H$, a decrease in the number of points by $50 \%$ was observed in $80.45 \%$ of patients with FD, $79.02 \%$ of patients with IBS, and in $83 \%$ of patients in the group with FD-IBS overlap (Table 3). 
Table 1 The distribution of patients categorized by severity of symptoms according to the " $7 * 7$ " questionnaire before treatment with the combination of RAF of Abs to S 100, Abs to TNF- $\mathrm{a}$ and $\mathrm{Abs}$ to $\mathrm{H}$

\begin{tabular}{ll}
\hline Severity category & Before treatment, $\mathrm{n}(\%)$ \\
\hline Healthy & 0 \\
Borderline ill & $383(4.13 \%)$ \\
Mildly ill & $2822(30.60 \%)$ \\
Moderately ill & $3236(34.96 \%)$ \\
Markedly ill & $1708(18.45 \%)$ \\
Severely ill & $1105(11.94 \%)$ \\
\hline
\end{tabular}

A decrease in the severity category of the condition at the end of therapy was noted in $93.34 \%$ of cases in patients with FD, in $93.81 \%$ of cases in patients with IBS, and in $96.17 \%$ of cases in patients with overlapping IBS and FD.

After 12 weeks of treatment with the combination of RAF of Abs to S 100, Abs to TNF- $\alpha$ and Abs to H, the distribution of patients according to the severity categories was as follows: 1930 patients (20.85\%) comprised the group "healthy", 4871 patients (52.63\%) - "borderline ill", 1915 patients $(20.69 \%)$ - "mildly ill", 435 patients (4.70\%) - "moderately ill", 78 patients $(0.84 \%)$ - "markedly ill", and 25 patients $(0.27 \%)$ - "severely ill" (Table 4, Fig. 1 ).

The distribution of patients according to severity categories in the groups with FD, IBS, and FDIBS overlap after therapy with the combination of RAF of Abs to $\mathrm{S}$ 100 , Abs to TNF- $\alpha$ and Abs to $\mathrm{H}$ is presented in Table 5.

In 159 (6.61\%) patients with FD, there was no change in the severity of symptoms; in 1 patient $(0.04 \%)$, there was a worsening of the state of health. The degree of severity of symptoms remained unchanged after therapy with the combination of RAF of Abs to S 100, Abs to TNF- $\alpha$ and Abs to $\mathrm{H}$ in 365 patients (6.18\%) with IBS; in 1 patient $(0.02 \%)$, a switch to a more "severe" group was observed. Symptom intensity did not change in 36 patients (3.83\%) with FD-IBS overlap; there were no patients who switched to a more "severe" category in this group.

In 2127 (88.48\%) patients with FD, there was a change in the score in domains 1 and 2, which characterize pain and a burning sensation in the upper middle part of the abdomen. The average score in domains 1 and 2 decreased by
4.47. In 2115 patients with FD (87.97\%), the average score in domains 3 and 4, which characterizes the syndrome of early satiety, also decreased by 3.5 (Table 6, Fig. 2).

In 5017 (84.9\%) patients with IBS, there was a decrease in the score in domain 5, which characterizes abdominal pain that decreases after a bowel movement. The decrease in the average score in this group was 2.41. Also in the majority of patients in the IBS group (87.31\%), there was a decrease in the score in domain 6, indicating a decrease in complaints of bloating. The average score in domain 6 decreased by 2.07. After 12 weeks of treatment with the combination of RAF of Abs to S 100, Abs to TNF- $\alpha$ and Abs to H, 5123 (86.70\%) patients reported a decrease in the number of complaints about the consistency and frequency of the stool. The average score in domain 7 decreased by 3.12 (Table 6, Fig. 2).

In patients with FD-IBS overlap, a decrease in the average score in each of the 7 domains was found. A decrease in pain and burning sensation was noted in 774 (82.25\%) patients with FD-IBS overlap: the average score in domains 1 and 2 decreased by 3.35. A decrease in the score in domains 3 and 4 (characterizing the syndrome of early satiety) was found in $783(83.21 \%)$ patients. In this category of patients, the average score decreased by 3.06. $725(77.05 \%)$ patients noted a decrease in the severity of pain after bowel movement. The average score in domain 5 decreased by 1.92 . After 12 weeks of treatment with the combination of RAF of Abs to S 100, Abs to TNF- $\alpha$ and Abs to H, 772 (82.04\%) patients had a decrease in the score in domain 6 , indicating a reduction in number of complaints of bloating. In this group, the average score decreased by 1.84 points. For 830 (88.20\%) patients, there was a decrease in scores in domain 7, which characterizes a change in the consistency and frequency of stools. The decrease in the average score was 3.17 (Table 6, Fig. 2).

\section{Safety evaluation}

A total of 94 adverse events (AEs) were recorded (Table 7) in 80 patients $(0.65 \%)$; or less than 1 case per 100 patients [25]. Most adverse events (55 cases, or $58.51 \%$ of all AEs) were associated with dysfunction of the digestive organs. Nausea was recorded most frequently, 22 cases of $\mathrm{AE}$,

Table 2 The categorization of severity among patients with FD, IBS, and FD-IBS overlap before treatment with the combination of RAF of Abs to S 100, Abs to TNF-a and Abs to H

\begin{tabular}{|c|c|c|c|c|c|c|c|}
\hline \multirow[t]{2}{*}{ Group } & & \multicolumn{6}{|c|}{ Severity category } \\
\hline & & Healthy & Borderline ill & Mildly ill & Moderately ill & Markedly ill & Severely ill \\
\hline $\begin{array}{l}F D \\
N=2404\end{array}$ & Before therapy $n(\%)$ & $0(0.0)$ & $161(6.69)$ & 778 (32.36) & 740 (30.78) & $431(17.92)$ & $294(12.22)$ \\
\hline $\begin{array}{l}\text { IBS } \\
N=5909\end{array}$ & Before therapy $n(\%)$ & $0(0,0)$ & $214(3.62)$ & $1911(32.34)$ & $2113(35.75)$ & $1036(17.53)$ & $635(10.74)$ \\
\hline $\begin{array}{l}\text { FD-IBS overlap } \\
N=941\end{array}$ & Before therapy $n(\%)$ & $0(0.0)$ & $8(0.85)$ & $133(14.13)$ & $383(40.70)$ & $241(25.61)$ & 176(18.70) \\
\hline
\end{tabular}


Table 3 The absolute number of patients with FD, IBS, and FD-IBS overlap, in which there was a decrease in the total score according to the questionnaire "7*7" by $50 \%$ or more after 12 weeks of therapy with the combination of RAF of Abs to S 100 , Abs to TNF-a and Abs to H

\begin{tabular}{lll}
\hline Group & The total number of patients in the group & $\begin{array}{l}\text { The number of patients in the group who } \\
\text { had a decrease in the total score by } \\
50 \% \text { or more, } \mathrm{n}(\%)\end{array}$ \\
\hline FD & 2404 & $1934(80.45 \%)$ \\
IBS & 5909 & $4669(79.02 \%)$ \\
FD-IBS overlap & 941 & $781(83 \%)$ \\
\hline
\end{tabular}

even though overall this type of $\mathrm{AE}$ is "infrequent" (0.15\%-i.e., less than 1 case per 100 patients), according to doctors, due to the nature of the course of FGID.

Less commonly recorded AEs involved the nervous system: 17 cases or $18.09 \%$ of all identified AEs, and were also "infrequent" $(0.11 \%)$.

AEs associated with skin diseases and subcutaneous fat were uncommon: 10 cases or $10.63 \%$ of all identified AEs, which were "rare" $(0.06 \%$, less than 1 case per 1000 patients).

Also recorded were general disorders (4 AEs, or 4.25\% of all identified AEs), nutritional and metabolic disorders (2 AEs, or $2.12 \%$ of all identified AEs), mental disorders and behavioral disorders (3 AEs, or $3.19 \%$ of all identified AEs) - all classified as "rare".

Two AEs associated with the musculoskeletal system and connective tissue (2.12\% of all identified AEs) and 1 $\mathrm{AE}$ associated with the circulatory system (1.06\% of all identified AEs) were recorded as well.

During the study period, no major AEs were identified. Also, no patients stopped taking the combination of RAF of Abs to S 100, Abs to TNF- $\alpha$ and Abs to H during the observation period.

\section{Discussion}

The COMFORT Observation Program has been completed in Russia with the participation of 14,362 patients. This program evaluated the efficacy and safety of the use of the combination of RAF of Abs to S 100, Abs to TNF- $\alpha$ and Abs to $\mathrm{H}$ in patients with FD, IBS, and FD-IBS overlap.

The distribution of patients with the FGID by gender in the COMFORT program corresponded to the data of population studies in Europe and North America [26, 27].
According to the literature, the majority of patients with FGID have abdominal symptoms of mild to moderate severity [28]. Similar trend was also observed in the present study: the majority of patients at the stage of inclusion described the severity of symptoms as "moderately ill".

The obtained results demonstrate that the combination of RAF of Abs to S 100, Abs to TNF- $\alpha$ and Abs to $\mathrm{H}$ has a pronounced therapeutic effect, reducing the intensity of symptoms of FGID by more than half in $80 \%$ of patients, which is consistent with previously obtained data in a multicenter, double-blind, placebo-controlled, randomized clinical trial of the efficacy and safety of using the combination of RAF of Abs to S 100, Abs to TNF- $\alpha$ and Abs to $\mathrm{H}$ for treating patients with IBS [23]. Along with a decrease in the intensity of abdominal pain, there was a normalization of the frequency and consistency of the stool, indicating a restoration of the motor-evacuation function of the GIT [23].

The previous study has also shown that the combination of RAF of Abs to S 100, Abs to TNF- $\alpha$ and Abs to $\mathrm{H}$ is effective in the treatment of patients with FD-IBS overlap: 12 weeks of therapy reduced the incidence of abdominal distention and nausea by 1.5 and 3 times compared with placebo [23].

According to Chen, the presence of coexisting FGID syndromes worsens their prognosis [29]. Long-term, prospective observation of patients with FD-IBS overlap showed that only $12 \%$ of them were able to achieve stable remission [30]. Therapy with the combination of RAF of Abs to S 100, Abs to TNF- $\alpha$ and Abs to $\mathrm{H}$ led to a greater increase in the number of patients in the "healthy" and "borderline ill" categories. The proportion of patients classified as "healthy" was $22.33 \%$

Table 4 The distribution of patients categorized by severity of symptoms according to the "7*7" questionnaire before and after 12 weeks of therapy with the combination of RAF of Abs to S 100, Abs to TNF-a and Abs to H

\begin{tabular}{lll}
\hline Severity category & Before treatment, $\mathrm{n}(\%)$ & After 12 weeks of therapy, $\mathrm{n}(\%)$ \\
\hline Healthy & 0 & $1930(20.85 \%)$ \\
Borderline ill & $383(4.13 \%)$ & $4871(52.63 \%)$ \\
Mildly ill & $2822(30.60 \%)$ & $1915(20.69 \%)$ \\
Moderately ill & $3236(34.96 \%)$ & $435(4.70 \%)$ \\
Markedly ill & $1708(18.45 \%)$ & $78(0.84 \%)$ \\
Severely ill & $1105(11.94 \%)$ & $25(0.27 \%)$ \\
\hline
\end{tabular}




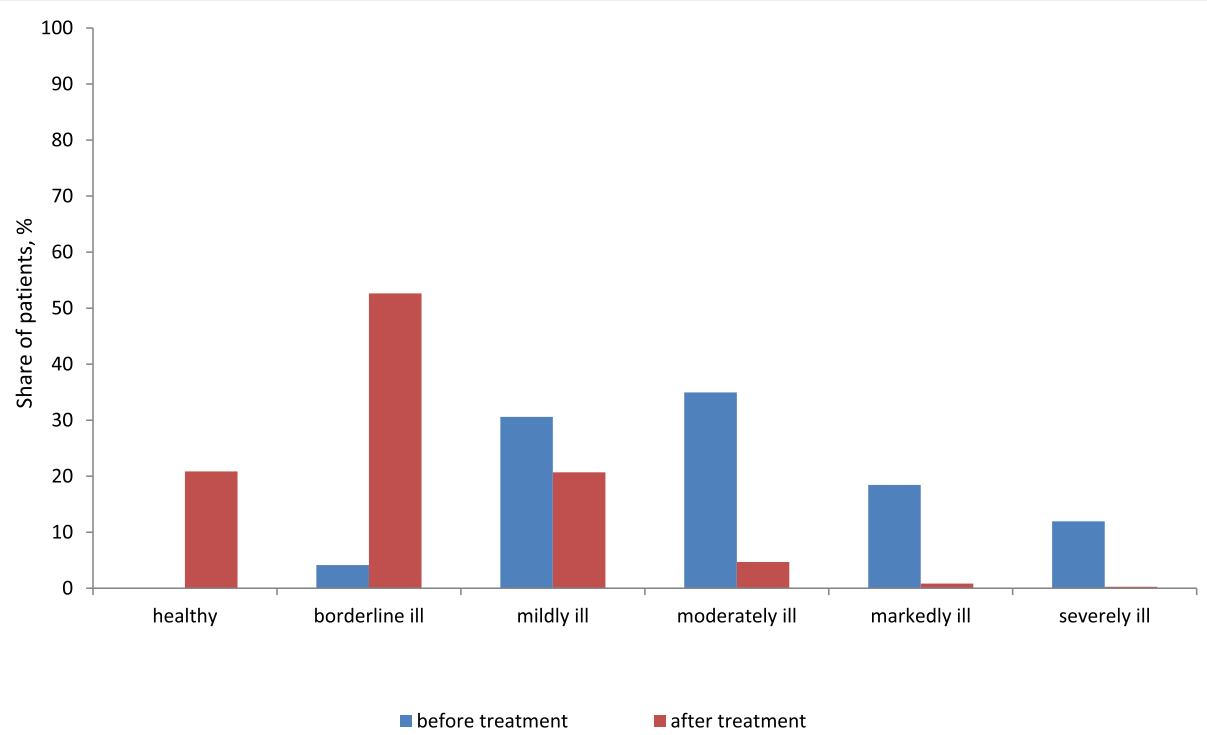

Fig. 1 The proportion of patients with FD, IBS, and FD-IBS overlap, categorized by severity of symptoms according to the "7*7" questionnaire, before and after 12 weeks of treatment with the combination of RAF of Abs to S 100, Abs to TNF-a and Abs to H

(537) in FD group; 20.93\% (1237) of in IBS group, and $16.57 \%$ (156) in FD-IBS overlap group. A "borderline ill" cohort consisted of 1339 patients (55.69\%) with FD, 3044 patients (51.51\%) with IBS, and 488 (51.85\%) patients with FDIBS overlap (Table 5).

Thus, the proportion of patients with no clinical manifestations of FGID was 77\% in FD group, 71\% in IBS group, and $68 \%$ in FD-IBS overlap group. Our findings contrast with the results of a systematic review of 22 studies evaluating the effectiveness of 12 antispasmodics in relieving symptoms of IBS in 1778 patients which revealed that 39\% of patients have persistent symptoms after therapy [31].

The observational program COMFORT showed a positive effect of the combination of RAF of Abs to $S 100$, Abs to TNF- $\alpha$ and Abs to $H$ in the majority of patients with FD-IBS overlap: in $83 \%$ of cases, there was a decrease in the total score of the "7*7" questionnaire by $50 \%$ or more. These results confirm the previously obtained data that treatment with the combination of RAF of Abs to S 100, Abs to TNF- $\alpha$ and $\mathrm{Abs}$ to $\mathrm{H}$ has a corrective effect on the manifestation of visceral sensitivity and nociceptive dysfunction [23].
Used as a tool for assessing the severity of symptoms of FD, the "7*7" questionnaire is convenient for the doctors and does not take much time from the patients [24]. According to the experience of practicing physicians, a detailed interview of a patient with FGID cannot take less than 45-60 min [32]. The "7*7" questionnaire used in this observational program is able to significantly minimize the time spent by a doctor when there is insufficient time allotted for the examination of the patient.

Similar international scales are often difficult to understand, need a long time to fill out the questionnaire, and are cluttered with terminology [33, 34].

The "7"7" questionnaire meets the requirements of the European Medical Agency, which recommends separately monitored stool frequency, bowel movement consistency, the severity of abdominal pain, and abdominal distention [35].

\section{Limitations}

There are limitations to our study that should be considered. Firstly, the observational nature of the program did not suggest the presence of a comparison group. However,

Table 5 The categorization of severity among patients with FD, IBS, and FD-IBS overlap before and after therapy with the combination of RAF of Abs to S 100, Abs to TNF-a and Abs to $\mathrm{H}$

\begin{tabular}{|c|c|c|c|c|c|c|c|}
\hline \multirow[t]{2}{*}{ Group } & & \multicolumn{6}{|c|}{ Severity category } \\
\hline & & Healthy & Borderline ill & Mildly ill & Moderately ill & Markedly ill & Severely ill \\
\hline \multirow{2}{*}{$\begin{array}{l}F D \\
N=2404\end{array}$} & Before therapy n (\%) & $0(0.0)$ & $161(6.69)$ & $778(32.36)$ & 740 (30.78) & $431(17.92)$ & $294(12.22)$ \\
\hline & After 12 weeks of therapy, $\mathrm{n}(\%)$ & $537(22.33)$ & $1339(55.69)$ & $406(16.88)$ & $99(4.11 \%)$ & $17(0.70)$ & $6(0.24)$ \\
\hline \multirow[t]{2}{*}{ IBS N=5909 } & Before therapy n (\%) & $0(0.0)$ & $214(3.62)$ & $1911(32.34)$ & $2113(35.75)$ & $1036(17.53)$ & $635(10.74)$ \\
\hline & After 12 weeks of therapy, $\mathrm{n}(\%)$ & $1237(20.93)$ & $3044(51.51)$ & $1304(22.06)$ & $267(4.51)$ & $43(0.72)$ & $14(0.23)$ \\
\hline \multirow[t]{2}{*}{ FD-IBS overlap N = 941} & Before therapy n (\%) & $0(0.0)$ & $8(0.85)$ & $133(14.13)$ & $383(40.70)$ & $241(25.61)$ & 176(18.70) \\
\hline & After 12 weeks of therapy, $\mathrm{n}(\%)$ & $156(16.57)$ & 488 (51.85) & $205(21.78)$ & $69(7.33)$ & 18 (1.91) & $5(0.53)$ \\
\hline
\end{tabular}


Table 6 The average score characterizing the severity of symptoms and their dynamics in domains 1-7 in patients with FD, IBS, and FD-IBS overlap

\begin{tabular}{|c|c|c|c|c|c|c|c|c|c|c|}
\hline \multirow[t]{3}{*}{ Domain } & \multirow[t]{3}{*}{ Symptom } & \multicolumn{9}{|c|}{ Patient groups } \\
\hline & & \multicolumn{2}{|c|}{$\mathrm{FD}$} & \multirow{2}{*}{$\begin{array}{l}\text { Severity } \\
\text { dynamics }\end{array}$} & \multicolumn{2}{|l|}{ IBS } & \multirow{2}{*}{$\begin{array}{l}\text { Severity } \\
\text { dynamics }\end{array}$} & \multicolumn{2}{|c|}{ FD-IBS overlap } & \multirow{2}{*}{$\begin{array}{l}\text { Severity } \\
\text { dynamics }\end{array}$} \\
\hline & & $\begin{array}{l}\text { Before } \\
\text { treatment, n } \\
\text { (\%) }\end{array}$ & $\begin{array}{l}\text { After } \\
\text { treatment }\end{array}$ & & $\begin{array}{l}\text { Before } \\
\text { treatment, n } \\
\text { (\%) }\end{array}$ & $\begin{array}{l}\text { After } \\
\text { treatment }\end{array}$ & & $\begin{array}{l}\text { Before } \\
\text { treatment, n } \\
\text { (\%) }\end{array}$ & $\begin{array}{l}\text { After } \\
\text { treatment }\end{array}$ & \\
\hline $1+2$ & Intensity of abdominal pain & 6.16 & 1.69 & 4.47 & - & - & - & 4.73 & 1.38 & 3.35 \\
\hline $3+4$ & Early satiety & 4.67 & 1.52 & 1.92 & - & - & - & 10.08 & 3.14 & 3.06 \\
\hline 5 & $\begin{array}{l}\text { Intensity of abdominal pain } \\
\text { after bowel movement }\end{array}$ & - & - & - & 3.37 & 0.96 & 2.41 & 2.76 & 0.84 & 1.92 \\
\hline 6 & Bloating & - & - & - & 3.11 & 1.04 & 2.07 & 2.77 & 0.93 & 1.84 \\
\hline 7 & $\begin{array}{l}\text { The consistency and the } \\
\text { frequency of stool }\end{array}$ & - & - & - & 4.78 & 1.66 & 3.12 & 4.55 & 1.37 & 3.17 \\
\hline
\end{tabular}

the value of this study is the maximum proximity to actual clinical practice and the possibility of obtaining additional data on the effectiveness of the drug in various FGID, including when they are combined.

Secondly, in the COMFORT program, patients with IBS were not subdivided into subtypes of IBS.

Inability to include the data of 5108 patients can be also considered as a limitation of the current study. At the same time, we should emphasize that some doctors might have experienced some difficulties with the filling of the various forms, thus the information on 3463 patients was missing. As previously mentioned, the data of 1645 patients with concomitant organic diseases of the GIT were not taken into account in the analysis of efficiency, since the overlap of these diagnoses can occur in case of their incorrect differential diagnosis. Furthermore, in accordance to Rome IV criteria these cases might be considered as secondary dyspepsia, which goes against the inclusion criteria. Another limitation of our study is related to the fact that the "7"7" questionnaire is a validated scale used only in Russia and is lacking international acceptance. Based on the accumulated experience, the ' $7 \times 7$ ' questionnaire can be recommended for use in clinical practice. It has been validated as a convenient, sensitive and reliable tool for assessing the severity of symptoms and their dynamics in treating patients with FGID, as well as for evaluating not only the improvement of the condition as the result of the treatment, but also the absence of changes or deterioration of the condition.

\section{Conclusions}

The results of the COMFORT observational program demonstrated the effectiveness of the combination of RAF of Abs to S 100, Abs to TNF- $\alpha$ and Abs to $\mathrm{H}$ in treating patients with FD, IBS, and overlapping IBS and

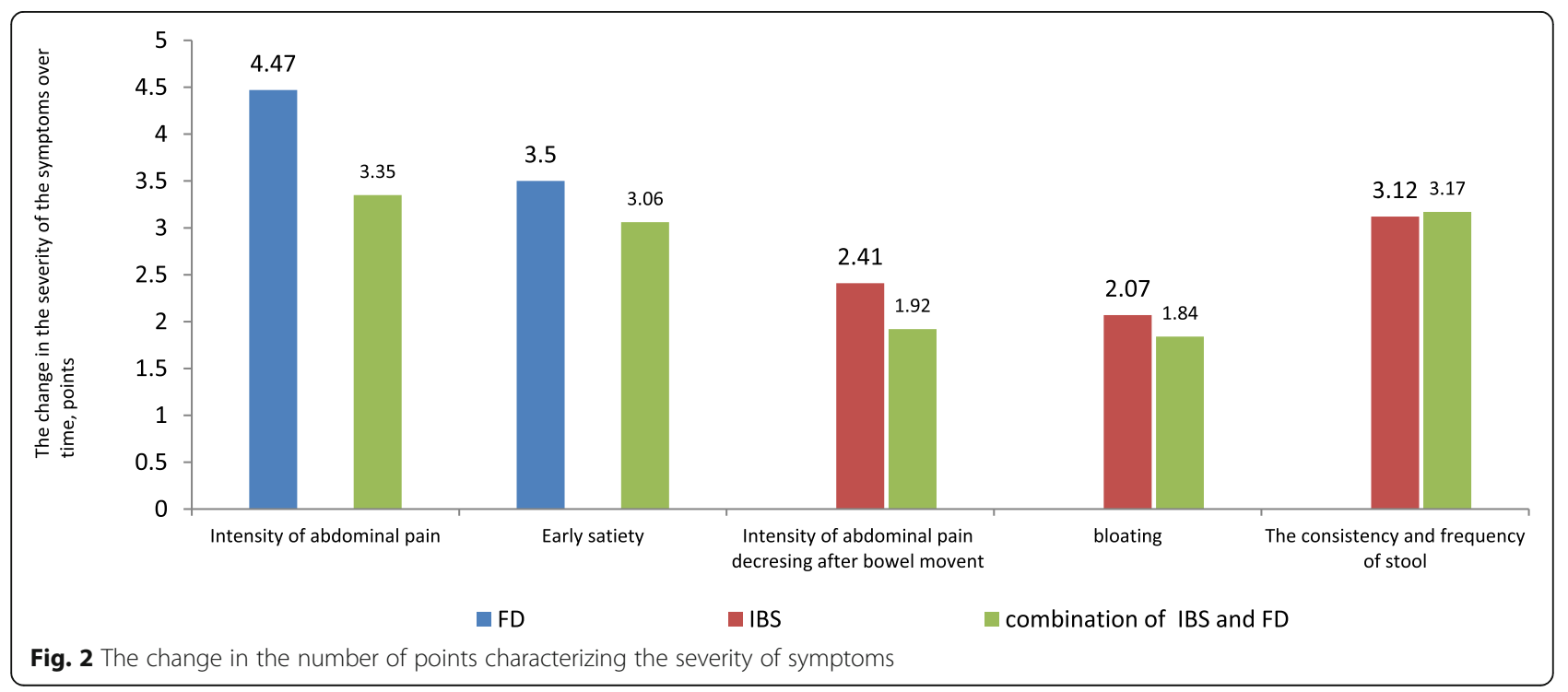


Table 7 Recorded Adverse Events

\begin{tabular}{|c|c|c|c|c|}
\hline \multirow[t]{3}{*}{ System organ class MedDRA } & Disease & Number of $A E$ & $\%$ of all patients & $\%$ of all $\mathrm{AE}$ \\
\hline & Total AE & 94 & 0.65 & 100.00 \\
\hline & $\mathrm{N}$ of patients who had at least $1 \mathrm{AE}$ & 80 & 0.55 & \\
\hline \multirow[t]{6}{*}{ Skin and subcutaneous tissue disorders } & Erythema & 1 & 0.007 & \\
\hline & Pruritus & 6 & 0.04 & \\
\hline & Rash & 1 & 0.007 & \\
\hline & Urticaria & 2 & 0.01 & \\
\hline & $\mathrm{N}$ of $\mathrm{AE}$ in this group & 10 & 0.06 & 10.63 \\
\hline & $\mathrm{N}$ of patients who had at least $1 \mathrm{AE}$ in this group & 8 & 0.05 & \\
\hline \multirow[t]{3}{*}{ Musculoskeletal and connective tissue disorders } & Myalgia & 2 & 0.0139 & \\
\hline & $N$ of $A E$ in this group & 2 & 0.0139 & 2.12 \\
\hline & $\mathrm{N}$ of patients who had at least $1 \mathrm{AE}$ in this group & 2 & 0.0139 & \\
\hline \multirow[t]{6}{*}{ Nervous system disorders } & Dizziness & 3 & 0.02 & \\
\hline & Dysgeusia & 2 & 0.01 & \\
\hline & Head discomfort & 1 & 0.007 & \\
\hline & Headache & 11 & 0.07 & \\
\hline & $N$ of $A E$ in this group & 17 & 0.11 & 18.09 \\
\hline & $\mathrm{N}$ of patients who had at least $1 \mathrm{AE}$ in this group & 15 & 0.10 & \\
\hline \multirow[t]{14}{*}{ Digestive system disorders } & Abdominal distension & 2 & 0.01 & \\
\hline & Abdominal pain & 14 & 0.09 & \\
\hline & Abdominal pain upper & 1 & 0.007 & \\
\hline & Anal pruritus & 1 & 0.007 & \\
\hline & Constipation & 4 & 0.02 & \\
\hline & Diarrhoea & 2 & 0.01 & \\
\hline & Dyschezia & 1 & 0.007 & \\
\hline & Dyspepsia & 1 & 0.007 & \\
\hline & Epigastric discomfort & 3 & 0.0209 & \\
\hline & Flatulence & 1 & 0.007 & \\
\hline & Nausea & 22 & 0.15 & \\
\hline & Tongue discomfort & 3 & 0.02 & \\
\hline & $\mathrm{N}$ of $\mathrm{AE}$ in this group & 55 & 0.38 & 58.51 \\
\hline & $\mathrm{N}$ of patients who had at least $1 \mathrm{AE}$ in this group & 51 & 0.35 & \\
\hline \multirow[t]{3}{*}{ Cardiac disorders } & Palpitations & 1 & 0.007 & \\
\hline & $N$ of $A E$ in this group & 1 & 0.007 & 1.06 \\
\hline & $\mathrm{N}$ of patients who had at least $1 \mathrm{AE}$ in this group & 1 & 0.007 & \\
\hline \multirow[t]{5}{*}{ General disorders and administration site conditions } & Asthenia & 2 & 0.01 & \\
\hline & Drug ineffective & 1 & 0.007 & \\
\hline & Feeling jittery & 1 & 0.007 & \\
\hline & $\mathrm{N}$ of $\mathrm{AE}$ in this group & 4 & 0.02 & 4.25 \\
\hline & $\mathrm{N}$ of patients who had at least $1 \mathrm{AE}$ in this group & 3 & 0.02 & \\
\hline \multirow[t]{4}{*}{ Psychiatric disorders } & Agitation & 2 & 0.01 & \\
\hline & Sleep disorder & 1 & 0.007 & \\
\hline & $N$ of $A E$ in this group & 3 & 0.02 & 3.19 \\
\hline & $\mathrm{N}$ of patients who had at least $1 \mathrm{AE}$ in this group & 2 & 0.01 & \\
\hline Metabolism and nutrition disorders & Decreased appetite & 1 & 0.007 & \\
\hline
\end{tabular}


Table 7 Recorded Adverse Events (Continued)

\begin{tabular}{|c|c|c|c|c|}
\hline \multirow[t]{3}{*}{ System organ class MedDRA } & Disease & Number of $A E$ & $\%$ of all patients & $\%$ of all $A E$ \\
\hline & Total AE & 94 & 0.65 & \multirow[t]{2}{*}{100.00} \\
\hline & $\mathrm{N}$ of patients who had at least $1 \mathrm{AE}$ & 80 & 0.55 & \\
\hline & Increased appetite & 1 & 0.007 & \multirow{3}{*}{2.12} \\
\hline & $N$ of $A E$ in this group & 2 & 0.01 & \\
\hline & $\mathrm{N}$ of patients who had at least $1 \mathrm{AE}$ in this group & 2 & 0.01 & \\
\hline
\end{tabular}

FD. In the absence of clear recommendations on overlap syndrome pharmacotherapy, an important conclusion of the study was the evidence of effective treatment of such patients.

The combination of RAF of Abs to S 100, Abs to TNF- $\alpha$ and Abs to $\mathrm{H}$ demonstrated good tolerability and the absence of negative effects on the patient's condition, which is important for long-term therapy of FGID.

\begin{abstract}
Abbreviations
Abs: Antibodies; AEs: Adverse events; FD: Functional dyspepsia; FGID: Functional gastrointestinal disorders; GIT: Gastrointestinal tract; IBS: Irritable bowel syndrome; IL: Interleukin; LLC "NPF "MATERIA MEDICA HOLDING": Limited Liability Company Research and Production Company Materia Medica Holding; RAF of Abs to H: RAF of Abs to histamine; RAF of Abs to S-100: RAF of antibodies to S 100 protein; RAF of Abs to TNF-a: RAF of antibodies to tumor necrosis factor-a; RAF: Released-active form; TNFa: Tumor necrosis factor-a
\end{abstract}

\section{Acknowledgments}

We thank Kovalchuk A.L. for valuable comments on the paper and language editing.

\section{Authors' contributions}

$\mathrm{VTI}$, EAP contributed to the study concept and design. ABG, MAP, OIE contributed to the data acquisition. EAP, VTI contributed to the data analyses and interpretation. EAP, VTI contributed to the drafting of the manuscript. All authors have read and approved the final draft of this manuscript.

\section{Funding}

The performed observational study in this publication was supported by the founder - Research and Production Company Materia Medica Holding (LLC "NPF «MATERIA MEDICA HOLDING»).The founder supported the COMFORT in process of obtaining information and database analyses.

\section{Availability of data and materials}

The conducted postmarketing surveillance study included data of 14362 outpatient's medical records. It is technically difficult to transfer such a vast amount of data. However, we are ready to give access to the data at the request of the reviewer after the evaluation of this article. In such case, we would kindly ask to provide us a non-disclosure agreement.

\section{Ethics approval and consent to participate}

According to GCP it is quite enough to obtain the approval at least the one for all sites. Since the huge numbers of medical organizations participated in the program it was decided to get unified approval accepted for non interventional study design by the Independent Interdisciplinary Ethics Committee on Ethical Review for Clinical Studies (hereinafter referred to as the "Committee"). The Committee is the independent local research ethic committee, which was established in 2000 by Moscow State University of Medicine and Dentistry, Russian Academy of Medical Sciences, Society for Pharmacoeconomics and Outcomes Research, League to support clinical studies and Scientific Center for medical information "Universimed", have made, executed and signed corresponding Agreement. The COMFORT was approved by the Committee (Protocol № 19 from 01.12.2017).

\section{Consent for publication}

Not applicable.

\section{Competing interests}

Prof. Glazunov and Dr. Putilovskiy authored this publication as employees of LLC "NPF" MATERIA MEDICA HOLDING". Prof. Epstein is the founder of LLC "NPF "MATERIA MEDICA HOLDING". Kolofort is a preparation manufactured and marketed by LLC "NPF" MATERIA MEDICA HOLDING". The authors report no other conflicts of interest in this work.

\section{Author details}

${ }^{1}$ I.M. Sechenov First Moscow State Medical University (Sechenov University), 8-2, Trubetskaya St, 119991 Moscow, Russian Federation. ${ }^{2}$ Department of Medical Information, Research and Production Company Materia Medica Holding LLC "NPF" MATERIA MEDICA HOLDING, 9, 3rd Samotyochny Per, Moscow, Russian Federation 127473. ${ }^{3}$ The Institute of General Pathology and Pathophysiology, 8, Baltiyskaya St, Moscow, Russian Federation 125315.

Received: 24 July 2019 Accepted: 11 December 2019

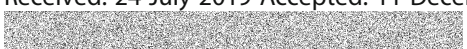

\section{References}

1. Lacy BE, Mearin F, Chang L, Chey W D, Lembo AJ, Simren M, Spiller R. Bowel Disorders. Gastroenterology. 2016;150(6):1393-407.e5.

2. Ivashkin VT, Mayev IV, Sheptulin AA, Alekseyeva OP, Baranskaya YK, Ivashkin KV, Kalinin AV, Korochanskaya NV, Kucheryavy YA, Lapina TL, Plotnikova YY, Poluektova YA, Simanenkov VI, Storonova OA, Tkachyov AV, Shifrin OS, Tarasova LV, Khlynov IB. The resolution of advisory council «how to improve treatment results functional dyspepsia and irritable bowel syndrome»? Russ J Gastroenterol Hepatol Coloproctol. 2016;26(2):101-4.

3. Trinkley K, Nahata M. Medication management of irritable bowel syndrome. Digestion. 2014;89(4):253-67.

4. Camilleri M. Medical therapies in the pipeline for irritable bowel syndrome. Gastroenterol Hepatol (N Y). 2017;13(9):550-2.

5. Pimentel M, Cash BD, Lembo A, Wolf RA, Israel RJ, Schoenfeld P. Repeat Rifaximin for irritable bowel syndrome: no clinically significant changes in stool microbial antibiotic sensitivity. Dig Dis Sci. 2017;62(9):2455-63.

6. Choi YJ, et al. Overlap between irritable bowel syndrome and functional dyspepsia including subtype analyses. J Gastroenterol Hepatol. 2017;32(9): 1553-61.

7. Fujiwara Y, Tetsuo A. Overlap in patients with dyspepsia/functional dyspepsia. J Neurogastroenterol Motil. 2014;20(4):447-57.

8. Corsetti M, Caenepeel P, Fischler B, Janssens J, Tack J. Impact of coexisting irritable bowel syndrome on symptoms and pathophysiological mechanisms in functional dyspepsia. Am J Gastroenterol. 2004;99(6):1152-9.

9. Padhy SK, Sahoo S, Mahajan S, Sinha S. Irritable bowel syndrome: is it "irritable brain" or "irritable bowel"? J Neurosci Rural Pract. 2015;6(4):568-77.

10. Park SH, Han KS, Kang CB. Relaxation therapy for irritable bowel syndrome: a systematic review. Asian Nurs Res. 2014;8(3):182-92.

11. Fadgyas-Stanculete M, Buga AM, Popa-Wagner A, Dumitrascu DL. The relationship between irritable bowel syndrome and psychiatric disorders: from molecular changes to clinical manifestations. J Mol Psychiatry. 2014;2(1):4.

12. Kawoos Y, Wani ZA, Kadla SA, Shah IA, Hussain A, Dar MM, Margoob MA, Sideeq K. Psychiatric co-morbidity in patients with irritable bowel syndrome at a tertiary care center in Northern India. J Neurogastroenterol Motil. 2017; 23(4):555-60.

13. Mayer EA. The role of gut-brain interactions in influencing of symptoms of IBS. Gastroenterol.Hepatol. (N.Y.). 2018;14(1):44-6. 
14. Pohl D, Oudenhove L, Törnblom H, Nevé B, Tack J, Simrén M. Functional Dyspepsia and Severity of Psychologic Symptoms Associate With Postprandial Symptoms in Patients With Irritable Bowel Syndrome. Clin Gastroenterol Hepatol. 2018;16(11):1745-1753.e1.

15. Patel SR, Singh A, Misra V, Misra SP, Dwivedi M, Trivedi P. Levels of interleukins 2, 6, 8, and 10 in patients with irritable bowel syndrome. Indian J Pathol Microbiol. 2017;60(3):385-9.

16. Seyedmirzaee S, Hayatbakhsh MM, Ahmadi B, Baniasadi N, Bagheri Rafsanjani AM, Nikpoor AR, Mohammadi M. Serum immune biomarkers in irritable bowel syndrome. Clin Res Hepatol Gastroenterol. 2016;40(5):631-7.

17. Madisch A, Andresen V, Enck P, Labenz J, Frieling T, Schemann M. The diagnosis and treatment of functional dyspepsia. Deutsches Arzteblatt Int. 2018;115(13):222-32

18. Camilleri M, Shin A, Busciglio I, Carlson P, Acosta A, Bharucha AE, Burton D, Lamsam J, Lueke A, Donato LJ, et al. Validating biomarkers of treatable mechanisms in irritable bowel syndrome. Neurogastroenterol Motil. 2014;26: 1677-85.

19. Ivashkin VT, Sheligyn YA, Baranskaya EK, et al. Clinical guidelines for irritable bowel syndrom treatment of the Russian Society of Coloproctology and the Russian gastroenterological association. Ross z Gastroenterol Gepatol Koloproktol. 2014:24(2):92-101.

20. von Wulffen M, Talley NJ, Hammer J, McMaster J, Rich G, Shah A, Koloski N, Kendall BJ, Jones M, Holtmann G. Overlap of irritable bowel syndrome and functional dyspepsia in the clinical setting: prevalence and risk factors. Dig Dis Sci. 2019;64:480.

21. Black CJ, Houghton LA, Ford AC. Insights into the evaluation and management of dyspepsia: recent developments and new guidelines. Ther Adv Gastroenterol. 2018:11:1756284818805597.

22. Jertuzun IA, Zueva EP, Krylova SG, Efimova LA, Dugina JL, Jepshtejn OI. Jeksperimental'noe izuchenie «Koloforta» - novogo preparata dlja lechenija sindroma razdrazhennogo kishechnika i drugih funkcional'nyh zabolevanij zheludochno-kishechnogo trakta. [Experimental study of preparation Kolofort a novel drug for treatment of irritable bowel syndrome and other functional gastrointestinal disorders]. Vestnik VolgGMU. 2012;4(44):S.25-7 Russian.

23. Avalueva EB, Adasheva TV, Babaeva AR, Burdina EG, Kireeva NV, Lenskaja LG, Osadchuk MA, Pahomova IG, Popova LI, Tkachenko El, Uspenskij JP, Shvarc JG, Myslivec AA, Andrianova EN. Jeffektivnost' i bezopasnost' primenenija Koloforta pri sindrome razdrazhennogo kishechnika: itogi mnogocentrovogo dvojnogo slepogo placebo-kontroliruemogo randomizirovannogo klinicheskogo issledovanija [Efficacy and safety of preparation Kolofort in treatment of irritable bowel syndrome:results of multicentral double blind placebo controlled clinical trial]. Consilium Medicum Gastrojenterologija. 2014:01(Suppl):43-50 Russian.

24. Ivashkin V, Sheptulin A, Shifrin O, Poluektova E, Pavlov C, Ivashkin K, Drozdova A, Lyashenko O, Korolev A. Clinical validation of the "7 $\times 7$ " questionnaire for patients with functional gastrointestinal disorders. J Gastroenterol Hepatol. 2019;34(6):1042-8.

25. Neubert A, Dormann H, Prokosch HU, Bürkle T, Rascher W, Sojer R, Brune K, Criegee-Rieck M. E-pharmacovigilance: development and implementation of a computable knowledge base to identify adverse drug reactions. Br J Clin Pharmacol. 2013;76(Suppl 1):69-77.

26. Cashman MD, Martin DK, Dhillon S, Puli SR. Irritable bowel syndrome: a clinical review. Curr Rheumatol Rev. 2016;12:13-26.

27. Enck P, Aziz Q, Barbara G, Farmer AD, Fukudo S, Mayer EA, Niesler B, Quigley EM, Rajilić-Stojanović M, Schemann M, Schwille-Kiuntke J, Simren M, Zipfel S, Spiller RC. Irritable bowel syndrome epidemiology, pathophysiology, diagnosis, and treatment. Nat Rev Dis Primers. 2016:2:16014.

28. Malfertheiner P. STW 5 (Iberogast) therapy in gastrointestinal functional disorders. Dig Dis. 2017;35(Suppl 1):25-9.

29. Chen F. Management of Overlap Syndrome between functional dyspepsia and irritable bowel syndrome by Western and traditional Chinese medicine. Yangtze Med. 2017;1:117-26.

30. Ford AC, Forman D, Bailey AG, Axon AT, Moayyedi P. Irritable bowel syndrome: a 10-yr natural history of symptoms and factors that influence consultation behavior. Am J Gastroenterol. 2008;103:1229-39.

31. Ford AC, Talley NJ, Spiegel BMR, Foxx-Orenstein AE, Schiller L, Quigley EMM, Moayyedi P. Effect of fibre, antispasmodics, and peppermint oil in the treatment of irritable bowel syndrome: systematic review and meta-analysis. BMJ. 2008;337(nov13 2):a2313-a2313.
32. Pogromov AP, Mnacakanjan MG, Tashhjan OV. Rasprostranennost' sindroma razdrazhennogo kishechnika. [Prevalence of irritable bowel syndrome]. Rossijskij zhurnal klinicheskoj mediciny. 2016;94(11):869-73. Russian.

33. Rabeneck L, Cook KF, Wristers K, Souchek J, Menke T, Wray NP. SODA (severity of dyspepsia assessment): a new effective outcome measure for dyspepsia-related health. J Clin Epidemiol. 2001;54(8):755-65.

34. Spiegel BM, Hays RD, Bolus R, Melmed GY, Chang L, Whitman C, Khanna PP, Paz SH, Hays T, Reise S, Khanna D. Development of the NIH patientreported outcomes measurement information system (PROMIS) gastrointestinal symptom scales. Am J Gastroenterol. 2014;109(11):1804-14.

35. Guideline on the evaluation of medicinal products for the treatment of irritable bowel syndrome EMA/CHMP/60337/2013. https:/www.ema.europa.eu/ documents/scientific-guideline/draft-guideline-evaluation-medicinal-productstreatment-irritable-bowel-syndrome-revision-1_en.pdf. Accessed 3 Jan 2019.

\section{Publisher's Note}

Springer Nature remains neutral with regard to jurisdictional claims in published maps and institutional affiliations.
Ready to submit your research? Choose BMC and benefit from:

- fast, convenient online submission

- thorough peer review by experienced researchers in your field

- rapid publication on acceptance

- support for research data, including large and complex data types

- gold Open Access which fosters wider collaboration and increased citations

- maximum visibility for your research: over $100 \mathrm{M}$ website views per year

At BMC, research is always in progress.

Learn more biomedcentral.com/submissions 